\title{
Ação antimicrobiana e influência de agentes desinfetantes sobre a reprodução de detalhes em silicona e compatibilidade com gesso
}

\author{
Antimicrobian action and influence of disinfectant agents on the reproduction of details in \\ silicon and plaster compatibility
}

Acción antimicrobiana e influencia de los agentes desinfectantes sobre la reproducción de detalles en el silicio y la compatibilidad con yeso

Luanna Abílio Diniz Melquíades de Medeiros ${ }^{1 *}$, Raquel Adriano Dantas², Elizandra Silva da Penha1, Rosana Araújo Rosendo¹, Camila Helena Machado da Costa Figueiredo', Gymenna Maria Tenório Guenes $^{1}$, Ana Karina Almeida Rolim³ ${ }^{3}$ Diego Filipe Bezerra Silva ${ }^{3}$, Maria Vitória Oliveira Dantas ${ }^{1}$, Cícero Romão Gadê Neto ${ }^{4}$.

\section{RESUMO}

Objetivo: Avaliar, in vitro, a ação antimicrobiana e a influência de agentes desinfetantes sobre a reprodução de detalhes de siliconas de moldagem (Elite HD+ e Zetaplus/Oranwash) e a compatibilidade com o gesso (Elite Rock). Métodos: $O$ estudo foi dividido em três partes: estudo da reprodução de detalhes, estudo da compatibilidade com o gesso e estudo da ação antimicrobiana. Para a reprodução de detalhes foram confeccionados, moldes em silicona de adição (Elite HD+) e silicona de condensação (Zetaplus/Oranwash) utilizando uma matriz conforme a especificação no 19 da ADA. Foram utilizadas 10 amostras para cada grupo, as quais foram desinfetadas com "sprays" das soluções desinfetantes (Hipoclorito de sódio 2,5\%, Glutaraldeído $2 \%$, Clorexidina $2 \%$, Ácido peracético $0,2 \%$ ), exceto àquelas do grupo controle. Resultados: Foi possível a observação da linha de $20 \pm 4 \mu \mathrm{m}$ de espessura em todos os moldes e modelos. Bem como, a não turvação dos meios de cultura contendo os moldes submetidos ao protocolo de desinfecção. Conclusão: O hipoclorito de sódio $2,5 \%$, glutaraldeído $2 \%$, clorexidina $2 \%$ e ácido peracético $0,2 \%$ possuem ação antimicrobiana sobre as siliconas testadas contaminadas com Staphylococcus aureus e não alteraram a reprodução de detalhes das mesmas, nem tampouco a sua compatibilidade com o gesso avaliado.

Palavras-chave: Desinfetantes, Moldagem, Modelos.

\section{ABSTRACT}

Objective: Evaluate in vitro antimicrobial action and the influence of disinfectants on the detail reproduction molding silicones (Elite HD + and Zetaplus / Oranwash) and compatibility with gypsum (Rock Elite). Methods: The study was divided into three parts: reproduction of detail study, examination of the compatibility with gypsum and study of the antimicrobial action. For the reproduction of detail was prepared, silicone molds addition (Elite HD +) and condensation silicone (Zetaplus / Oranwash) using a matrix according to ADA specification \# 19. To do this, 10 samples were used for each group, which were disinfected with "spray" of disinfectant solutions ( $2.5 \%$ sodium hypochlorite, $2 \%$ glutaraldehyde, $2 \%$ chlorhexidine, peracetic acid $0.2 \%$ ), other than those of group control. Results: It was possible to visualize the $20 \pm 4 \mu \mathrm{m}$ thick line in every mold

\footnotetext{
1 Universidade Federal de Campina Grande (UFCG), Patos-Paraíba. *E-mail: Iuannaabiliod@gmail.com

2 Faculdade São Leopoldo Mandic, Campinas-São Paulo.

3 Universidade Estadual da Paraíba (UEPB), Campina Grande-Paraíba.

${ }^{4}$ Faculdade Mineira (UNIMINAS), Uberlândia-Minas Gerais.
} 
and models. As well, the non-clouding of the culture media containing the molds subjected to disinfection protocol. Conclusion: The $2.5 \%$ of sodium hypochlorite, $2 \%$ glutaraldehyde, $2 \%$ chlorhexidine and $0.2 \%$ peracetic acid possess antimicrobial action on the tested silicones contaminated with Staphylococcus aureus and not changed playback details of they nor their compatibility with the rated gypsum.

Keywords: Disinfectants, Dental impression, Dental models.

\section{RESUMEN}

Objetivo: Evaluar in vitro la acción antimicrobiana y la influencia de los agentes desinfectantes en la reproducción de los detalles de moldeo de silicio (Elite HD + y Zetaplus / Oranwash) y la compatibilidad del yeso (Elite Rock). Métodos: El estudio se dividió en tres partes: estudio de reproducción de detalles, estudio de compatibilidad con yeso y estudio de acción antimicrobiana. Para la reproducción de detalles, se hicieron moldes además de silicio (Elite HD +) y silicio de condensación (Zetaplus / Oranwash) utilizando una matriz de acuerdo con la especificación ADA no 19. Se usaron diez muestras para cada grupo, que se desinfectaron con aerosoles de soluciones desinfectantes (hipoclorito de sodio al $2.5 \%$, glutaraldehído al $2 \%$, clorhexidina al $2 \%$, ácido peracético al $0.2 \%$ ), excepto las del grupo de control. Resultados: Fue posible observar la línea de $20 \pm 4 \mu \mathrm{m}$ de espesor en todos los moldes y modelos. Además de la no turbidez de los medios de cultivo que contienen los moldes sometidos al protocolo de desinfección. Conclusión: El hipoclorito de sodio al 2.5\%, el glutaraldehído al $2 \%$, la clorhexidina al $2 \%$ y el ácido peracético al $0.2 \%$ tienen acción antimicrobiana en las siliconas probadas contaminadas con Staphylococcus aureus y no alteraron la reproducción de sus detalles ni su uso. compatibilidad con el yeso evaluado.

Palabras clave: Desinfectantes, Moldeo, Modelos.

\section{INTRODUÇÃO}

Com o surgimento de doenças infecto-contagiosas de alta morbidade e mortalidade, a exemplo da Síndrome da Imonodeficiência Adquirida (AIDS), a Odontologia passou a se preocupar mais com questões relacionadas à Biossegurança, porém alguns procedimentos de proteção, a exemplo a descontaminação, desinfencção e esterilização, ainda são negligenciados (TSUZUKI FM, et al., 2019; YADAV BK, et al., 2017). Este fato pode ser mais crítico ainda quando se trata de procedimentos não invasivos, tais como as moldagens (SILVA TSDO, et al., 2016).

A American Dental Association recomenda que materiais de laboratório que tenham contato com cavidade bucal, como por exemplo, moldes, registro de mordida, próteses, aparelhos ortodônticos, como também os modelos sejam desinfetados antes do envio para o laboratório e vice-versa (ADA, 1996). Pois, estes são contaminadas por saliva, biofilme e algumas vezes até por sangue, podendo desta forma servir como disseminadores de doenças infecciosas (NASSAR U, et al., 2015; SAVABI O, et al., 2018). Porém é necessário que essa desinfecção não interfira nas propriedades físico-químicas dos materiais de moldagem, tais como capacidade de reprodução de detalhes, estabilidade dimensional e grau de umedecimento entre outros fatores de extrema importância no caso dos elastômeros (mercaptana, silicona ou poliéter) visto que os trabalhos produzidos sobre esses moldes necessitam de grande precisão (ABINAYA K, et al., 2018; POULIS N, et al., 2016; QUEIROZ GL, et al., 2019).

Diante da necessidade de se evitar a infecção cruzada entre pacientes e equipe odontológica, é necessário que haja uma maior conscientização dos indivíduos e maior divulgação de métodos eficazes de desinfecção a serem adotados nos consultórios odontológicos e também nos laboratórios de prótese dentária (YADAV BK, et al., 2017). Existem diferentes substâncias utilizadas para desinfecção em Odontologia, dentre elas destacam-se a clorexidina, o hipoclorito de sódio, o glutaraldeído e o ácido peracético. E diferentes maneiras de aplicar tais substâncias, seja nos moldes ou nos modelos de gesso, ou ainda pela incorporação de agentes antimicrobianos à composição do gesso (GUIRALDO RD, et al., 2016; GUPTA R, et al., 2016; POULIS N, et al., 2016). 
Sabe-se que vários fatores relacionados ao agente desinfetante como: tipo e concentração, técnica de aplicação e tempo de utilização do produto; podem causar alterações no material de moldagem e produzir modelos de gesso alterados; o que poderá comprometer a qualidade do trabalho sobre ele realizado (GUIRALDO RD, et al., 2017). Assim sendo, o propósito desse trabalho foi avaliar a ação antimicrobiana e a influência de agentes desinfetantes sobre a reprodução de detalhes e a compatibilidade com o gesso. Visto que, as substâncias utilizadas para desinfecção de moldes necessitam ter um poder antimicrobiano, sem, no entanto, alterar o material de moldagem ou o modelo de gesso sobre ele construído.

\section{MÉTODOS}

Trata-se de um estudo experimental, cuja metodologia foi dividida em três etapas. Tendo sido avaliado a reprodução dos detalhes nas siliconas, a compatibilidade com gesso e a ação antimicrobiana das substâncias desinfetantes (Figura 1). Para tanto os materiais avaliados foram silicona de adição (Elite HD+: Zhermack) e silicona de condensação (Zetaplus/Oranwash: Zhermack), gesso tipo IV (Elite rock: Zhermack) e, por fim, os desinfetantes hipoclorito de sódio 2,5\% (Asfer Indústria química), glutaraldeído 2\% (Technew), clorexidina 2\% (FGM) e ácido peracético 0,2\% (Lifemed)

Figura 1 - Fluxograma do delineamento experimental.

REPRODUÇÃO DE DETALHES EM SILICONA

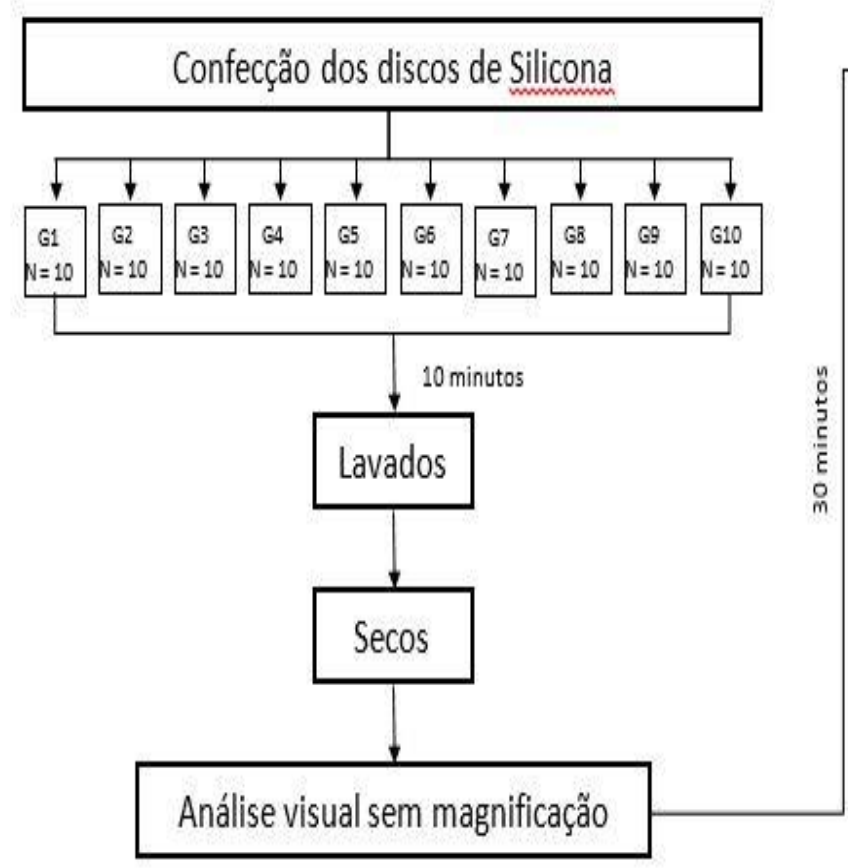

COMPATIBILIDADE COM O GESSO

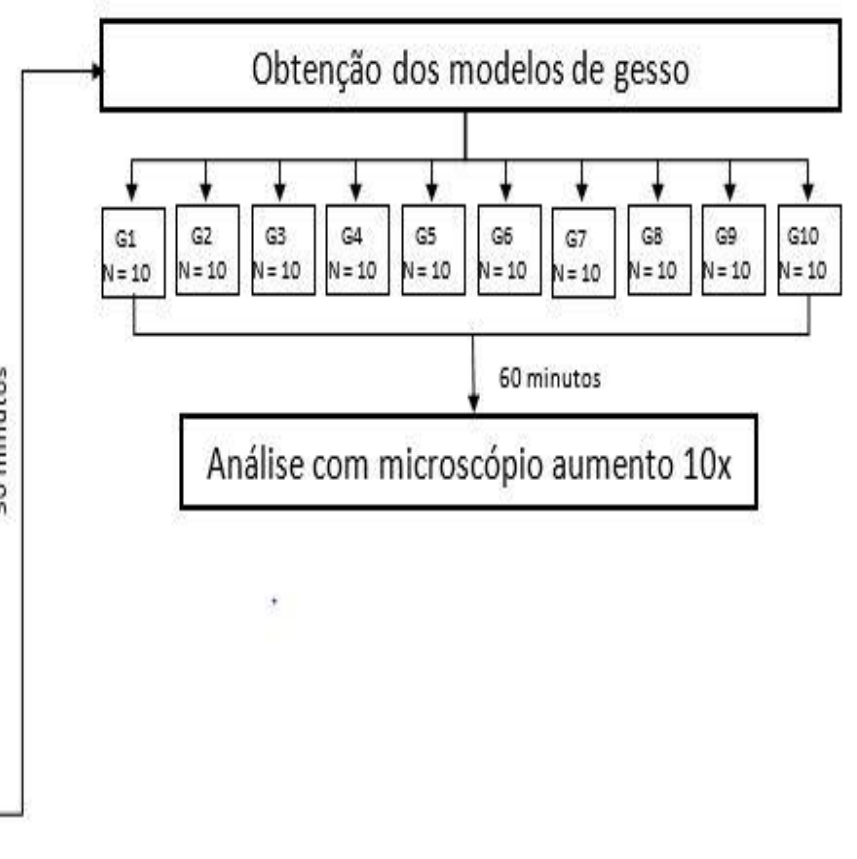

Fonte: Medeiros LADM, et al., 2016.

Para a realização da primeira e segunda etapas, isto é, a avaliação da reprodução dos detalhes na silicona e compatibilidade destas com o gesso; foram formados 10 grupos, com 10 amostras cada $(n=10)$, sendo representados conforme pode ser observado na Tabela 1. As mesmas nomenclaturas foram usadas para os grupos onde foram observadas a compatibilidade com o gesso das siliconas de moldagem submetidas aos protocolos de desinfecção, porém o que foi avaliado foram os modelos obtidos após o vazamento com gesso de cada um dos grupos descritos acima. 
Tabela 1 - Grupos amostrais da primeira e segunda etapas.

\begin{tabular}{c|c}
\hline & Grupos \\
\hline G1 & G1- Elite HD+ desinfectado com Hipoclorito de sódio 2,5\% \\
G2 & G2-Elite HD+ desinfectado com Glutaraldeído $2 \%$ \\
G3 & G3- HD+ desinfectado com Clorexidina $2 \%$ \\
G4 & G4- HD+ não desinfectado \\
G5 & G5- Zetaplus + Oranwash desinfectado com Hipoclorito de sódio 2,5\% \\
G6 & G6- Zetaplus + Oranwash desinfectado com Glutaraldeído 2\% \\
G7 & G7- Zetaplus + Oranwash desinfectado com Clorexidina \\
G8 & G8- Zetaplus + Oranwash não desinfectado \\
G9 & G9- Zetaplus + Oranwash desinfectado com Ácido peracético $0,2 \%$ \\
G10 & G10- HD+ desinfectado com Ácido peracético $0,2 \%$ \\
\hline
\end{tabular}

Fonte: Medeiros LADM, et al., 2016.

Para a avaliação da atividade antimicrobiana, in vitro, foram formados 12 grupos com três amostras cada. O meio de cultura utilizado foi BHI (Brain Heart Infusion) caldo (Difco) no intuito de verificar contaminação pelo Staphylococcus aureus. Os grupos formados foram os observados na Tabela 2.

Tabela 2 - Grupos amostrais da terceira etapa.

\begin{tabular}{|c|c|}
\hline \multicolumn{2}{|r|}{ GRUPOS } \\
\hline G1 & $\begin{array}{l}\text { Elite HD+ contaminado com Staphylococcus aureus e desinfectado com Hipoclorito de sódio } \\
\qquad 2,5 \%\end{array}$ \\
\hline G2 & Elite HD+ contaminado com Staphylococcus aureus e desinfectado com Glutaraldeído $2 \%$ \\
\hline G3 & HD+ contaminado com Staphylococcus aureus e desinfectado com Clorexidina $2 \%$ \\
\hline G4 & HD+ não contaminado com Staphylococcus aureus e não desinfectado (controle negativo) \\
\hline G5 & HD+ contaminado com Staphylococcus aureus e não desinfectado (controle positivo) \\
\hline G6 & $\begin{array}{c}\text { Zetaplus + Oranwash contaminado com Staphylococcus aureus e desinfectado com Hipoclorito } \\
\text { de sódio } 2,5 \%\end{array}$ \\
\hline G7 & $\begin{array}{c}\text { Zetaplus + Oranwash contaminado com Staphylococcus aureus e desinfectado com } \\
\text { Glutaraldeído } 2 \%\end{array}$ \\
\hline G8 & $\begin{array}{c}\text { Zetaplus + Oranwash contaminado com Staphylococcus aureus e desinfectado com Clorexidina } \\
\qquad 2 \%\end{array}$ \\
\hline G9 & $\begin{array}{l}\text { Zetaplus + Oranwash não contaminado com Staphylococcus aureus e não desinfectado } \\
\text { (controle negativo) }\end{array}$ \\
\hline G10 & $\begin{array}{c}\text { Zetaplus + Oranwash contaminado com Staphylococcus aureus e não desinfectado (controle } \\
\text { positivo) }\end{array}$ \\
\hline G11 & $\begin{array}{c}\text { Zetaplus + Oranwash contaminado com Staphylococcus aureus e desinfectado com Ácido } \\
\text { peracético } 0,2 \%\end{array}$ \\
\hline G12 & HD+ contaminado com Staphylococcus aureus e desinfectado com Ácido peracético $0,2 \%$ \\
\hline
\end{tabular}

Fonte: Medeiros LADM, et al., 2016.

A primeira etapa teve o intuito de avaliar, in vitro, a reprodução de detalhes dos moldes de silicona de moldagem (50 moldes de silicona de adição e 50 moldes de silicona de condensação) após o protocolo de desinfecção. Para isso foram confeccionados discos de silicona, seguindo as instruções do fabricante, utilizando uma matriz cilíndrica com $38 \mathrm{~mm}$ de diâmetro externo, $30 \mathrm{~mm}$ de diâmetro interno conforme a especificação oㅡ 19 da American Dental Association (ADA). A mesma possui na superfície superior três linhas paralelas entre si com $30 \mathrm{~mm}$ de comprimento cada uma e $75 \pm 8 \mu \mathrm{m}, 20 \pm 4 \mu \mathrm{m}$ e $50 \pm 8 \mu \mathrm{m}$ de largura respectivamente. Foi ainda confeccionada uma moldeira circular perfurada perfeitamente adaptada à superfície superior da matriz. A técnica de moldagem utilizada foi em fase única, de modo que a moldeira contendo a massa pesada foi posicionada e pressionada sobre a matriz contendo a massa leve, após o posicionamento foi realizada uma pressão digital. E em seguida o conjunto foi levado a uma prensa hidráulica com uma carga de 0,5 toneladas. Sendo aguardado o período de 3.5 minutos, recomendado pelo fabricante, 
acrescido de 3 minutos, conforme a especificação ํo 19 da ADA, para a liberação da prensa e posterior remoção cuidadosa da moldeira a fim de se evitar distorções no molde (SILVA SMLM e SALVADOR MCG, 2004).

Esses discos foram divididos em grupos e submetidas à aplicação de "sprays" das soluções desinfetantes (Hipoclorito de sódio 2,5\%, Glutaraldeído $2 \%$, Clorexidina $2 \%$, Ácido peracético $0,2 \%$ ), exceto àquelas do grupo controle. Após aplicação do "spray" (5 vezes seguidas) os moldes foram mantidos em sacos plásticos hermeticamente fechados por 10 minutos. Em seguida lavados em água corrente por 1 minuto a $15 \mathrm{~cm}$ de distância e secos com ar comprimido numa distância de $15 \mathrm{~cm}$ por 20 segundos, exceto o grupo controle de cada material nos quais não foram aplicados substância desinfetante (QUEIROZ GL, et al., 2019). Quando então se procedeu à análise visual sem magnificação da superfície dos moldes a fim de se observar a linha de $20 \pm 4 \mu \mathrm{m}$ de espessura, o que significa que foi mantida a reprodução de detalhes do material.

Decorridos 30 minutos a segunda etapa do estudo foi realizada. Os moldes foram vazados com gesso tipo IV (Elite rock), conforme as instruções dos fabricantes dos materiais de impressão. Para possibilitar tal vazamento foram confeccionados anéis de cera $7 \mathrm{com} 2 \mathrm{~cm}$ de altura os quais foram fixados ao redor do molde. O gesso foi inserido em pequenas porções com o auxílio de uma espátula 7 sob vibração (GUPTA R, et al., 2016). Aguardou-se cristalização do gesso por 60 minutos em uma embalagem plástica fechada com umidade de $100 \%$. Os modelos foram analisados de modo cego, por três observadores, após 24 horas. Utilizando-se um microscópio com um aumento de 10X, sendo a compatibilidade com o gesso considerada satisfatória quando foi possível visualizar a linha (central) de $20 \pm 4 \mu \mathrm{m}$ e $30 \mathrm{~mm}$ de comprimento de forma contínua em pelo menos dois de cada três modelos de gesso.

E a terceira etapa do estudo consistiu na avaliação da atividade antimicrobiana, in vitro, das substâncias desinfetantes sobre os materiais de moldagem. Para tanto, foram utilizados para a confecção dos moldes de silicone, cilindros plásticos previamente esterilizados, e materiais de moldagem manipulados segundo as instruções dos fabricantes. Utilizou-se seringas descartáveis de $1 \mathrm{~mL}$, as quais foram seccionadas em um torno mecânico de modo a gerar dois cilindros com $23 \mathrm{~mm}$ de comprimento cada um. Esses cilindros previamente esterilizados foram utilizados para a confecção dos corpos de prova das siliconas. O material de consistência pesada foi pressionado contra o cilindro e adaptado até a metade do mesmo com o auxílio do êmbolo da própria seringa de $1 \mathrm{~mL}$ sem a borracha, enquanto que o material de consistência leve foi inserido no cilindro com o auxílio de uma seringa para elastômeros no caso da silicona de condensação e com um dispositivo de auto-mistura no caso da silicona de adição.

Foi aguardado o período de 3,5 minutos recomendado pelo fabricante, acrescido de 3 minutos, conforme a especificação no 19 da ADA, para a remoção do molde (SILVA SMLM e SALVADOR MCG, 2004). Para a remoção dos moldes, também foi utilizado o êmbolo da seringa de $1 \mathrm{~mL}$.

Esses cilindros de elastômeros foram contaminados durante 7 minutos em solução contendo Staphylococcus aureus na escala 10 de MacFarland, exceto o controle negativo e em seguida permaneciam imersos em solução estéril por 30 segundos. Feito isso, procedeu-se o protocolo de desinfecção, isto é, cada um recebeu 5 sprays, abrangendo todas as superfícies do cilindro, da substância desinfetante correspondente ao grupo a que pertenciam e mantidas em sacos plásticos fechados por 10 minutos. Em seguida os corpos de prova foram imersos em $40 \mathrm{~mL}$ de solução estéril por 30 segundos e secos com gaze esterilizada por 20 segundos, exceto as amostras do grupo controle de cada material, nas quais não foram aplicadas nenhuma substância desinfetante. Após tais procedimentos os corpos de prova foram colocados em tubos de ensaio contendo meio de cultura estéril BHI estéril e incubados em estufa microbiológica (Quimis) a 37ํㅡ por 24 horas. Decorrido esse tempo, avaliou-se a presença ou ausência de turvação dos meios contendo os materiais de moldagem. Sendo considerado eficiente o protocolo de desinfecção na ausência de turvação do meio.

\section{RESULTADOS}

Como resultado da primeira etapa, constatou-se que as siliconas de moldagem Elite HD+ (G1, G2, G3, G4, G10) e Zetaplus/Oranwash (G5, G6, G7, G8, G9) mantiveram a fiel reprodução dos detalhes após a 
desinfeção com Hipoclorito de sódio 2,5\%, Glutaraldeído 2\%, Clorexidina 2\%, Ácido peracético 0,2\% (Gráfico 1). Uma vez que foi possível a visualização da linha (central) de $20 \pm 4 \mu \mathrm{m}$ de espessura e $30 \mathrm{~mm}$ de comprimento de forma contínua em todos os moldes (Figura 2).

Gráfico 1 - Observação a olho nu da linha (central) de $20 \pm 4 \mu \mathrm{m}$ e $30 \mathrm{~mm}$ de comprimento de forma contínua nos moldes de silicona.

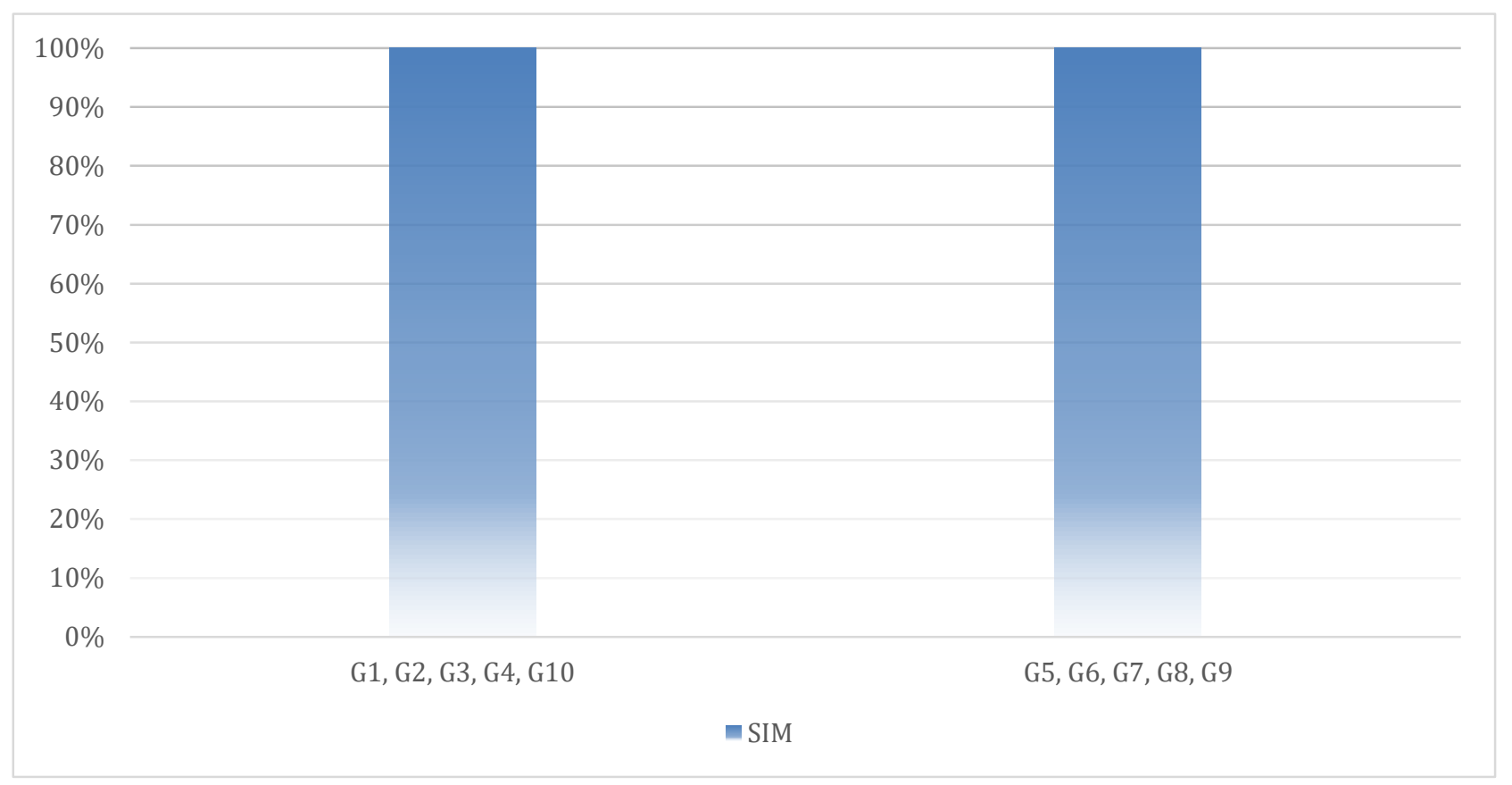

Fonte: Medeiros LADM, et al., 2016.

Figura 2 - Moldes evidenciando a linha de $20 \pm 4 \mu \mathrm{m}$ e $30 \mathrm{~mm}$ de comprimento de forma contínua.

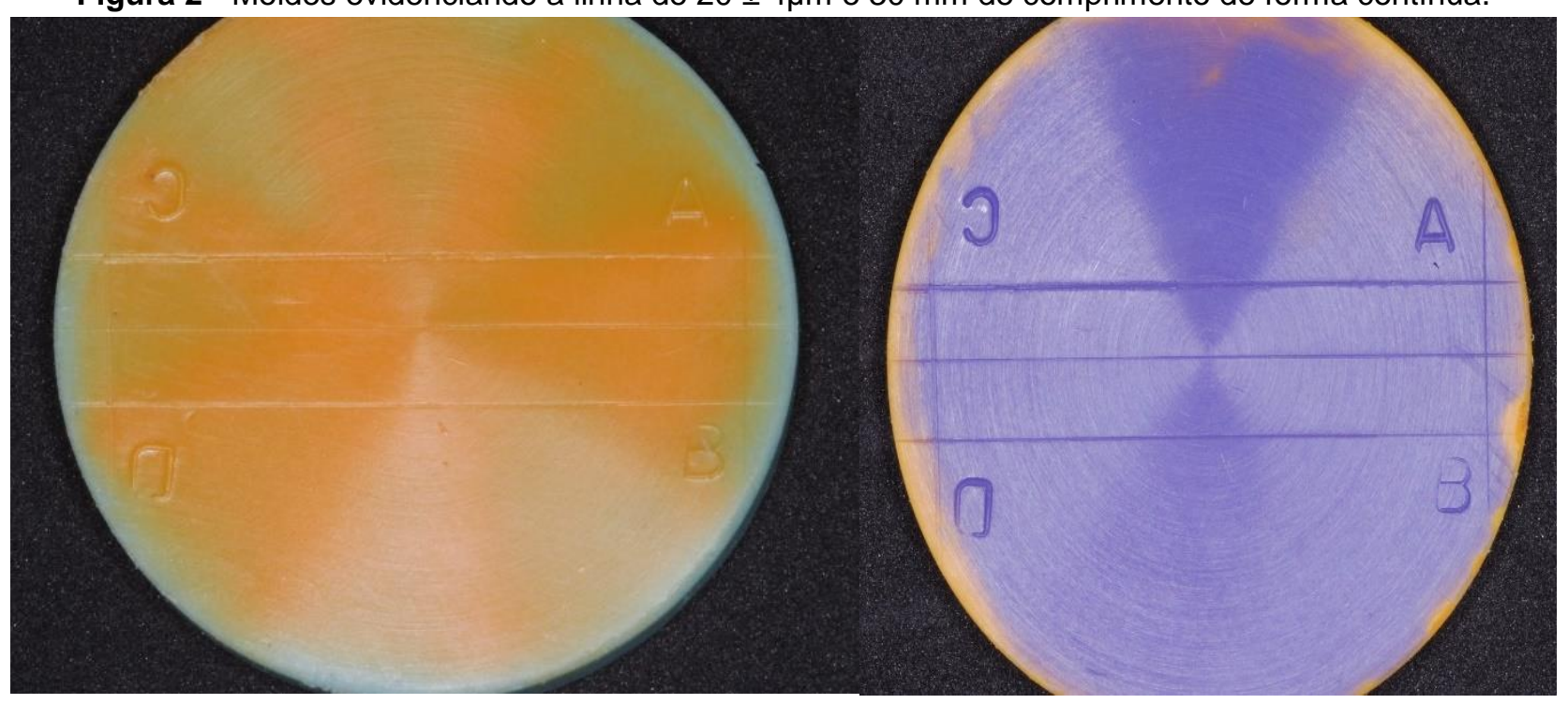

Fonte: Medeiros LADM, et al., 2016.

Como resultado da segunda etapa (Gráfico 2) foi avaliada a compatibilidade com o gesso e a mesma foi considerada satisfatória, pois foi possível visualizar a linha (central) de $20 \pm 4 \mu \mathrm{m}$ e $30 \mathrm{~mm}$ de comprimento de forma contínua. Para a análise foi utilizado um microscópio operatório (DF Vasconcellos) com um aumento de $10 x$. 
Gráfico 2 - Observação com o microscópio clínico com 10X de aumento da linha (central) de $20 \pm 4 \mu \mathrm{m}$ e $30 \mathrm{~mm}$ de comprimento.

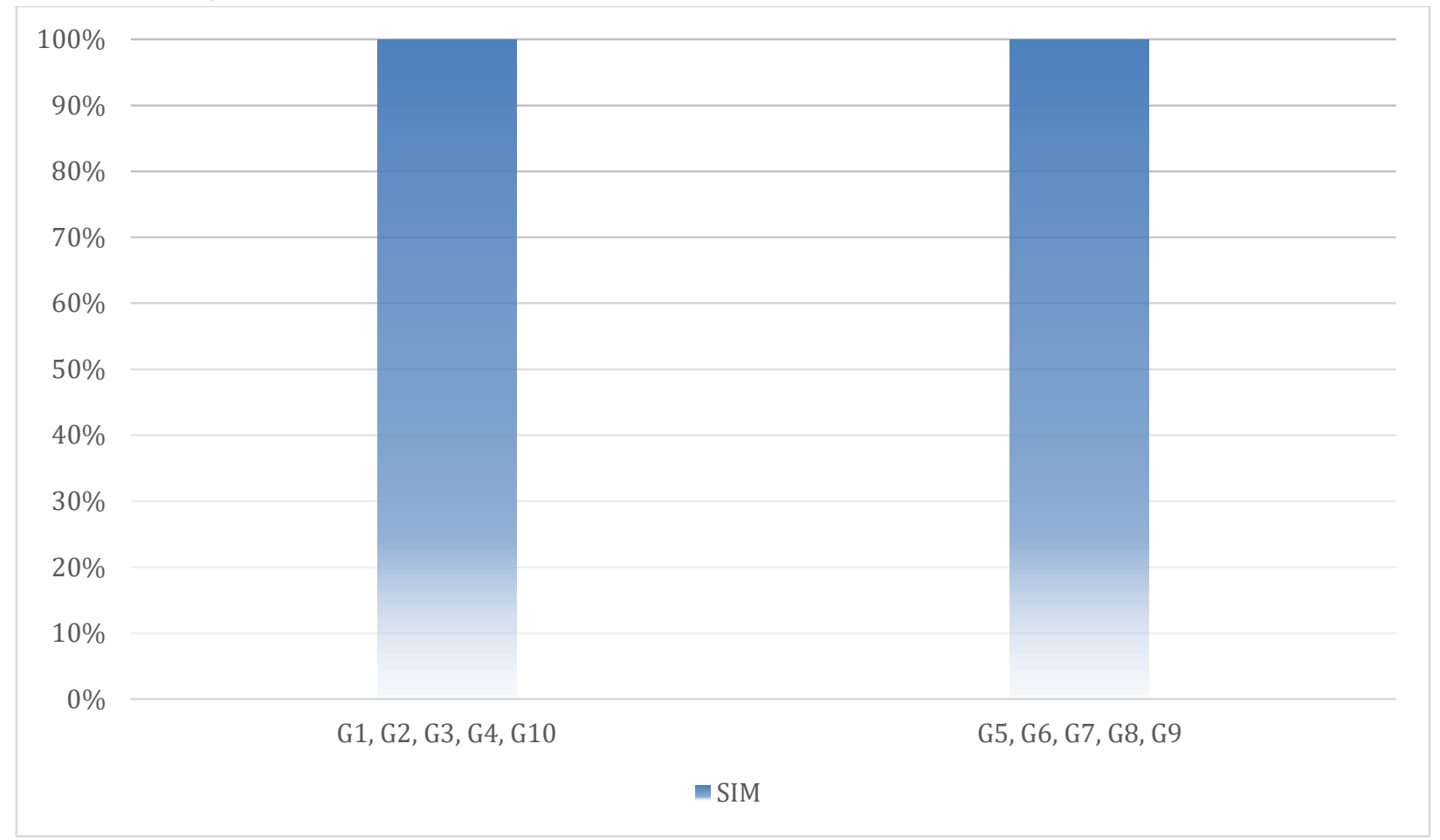

Fonte: Medeiros LADM, et al., 2016.

Foi observado, na terceira etapa, a turvação dos grupos controles positivos (G5 e G10) e a não turvação dos meios de cultura contendo os moldes submetidos ao protocolo de desinfecção (G1, G2, G3, G6, G7, G8, G11 e G12) bem como dos controles negativos (G4 e G9). A Tabela 3 mostra a eficiência do protocolo de desinfecção.

Tabela 3 - Porcentagem de turvação do meio de cultura contendo os corpos de prova.

\begin{tabular}{c|c} 
G1 & $0 \%$ \\
G2 & $0 \%$ \\
G4 & $0 \%$ \\
G5 & $0 \%$ \\
G6 & $100 \%$ \\
G7 & $0 \%$ \\
G8 & $0 \%$ \\
G9 & $0 \%$ \\
G10 & $0 \%$ \\
G11 & $100 \%$ \\
G12 & $0 \%$ \\
\hline
\end{tabular}

Fonte: Medeiros LADM et al. 2016

Diante dos resultados obtidos não foi necessária a análise estatística, visto que os dados não variaram, ou seja, todos os métodos de desinfecção tiveram a mesma eficiência. 


\section{DISCUSSÃO}

No presente estudo foi observado a reprodução de detalhes em $100 \%$ dos moldes de silicona, independente de serem confeccionados em silicona de adição (Elite HD+) ou silicona de condensação (Zetaplus/Oranwash) e da substância desinfetante utilizada, pelo tempo de 10 minutos. Resultado semelhante foi observado no estudo de Vasconcellos FC, et al. (2012), ao compararem a estabilidade dimensional de modelos obtidos com poliéter e silicone de adição, após desinfecção, apesar de ter sido realizada pelo tempo de 30 minutos. O tempo de 10 minutos para desinfecção é considerado suficiente para descontaminação dos fluidos bucais sem gerar alterações significativas na estabilidade dimensional dos materiais (YLMAZ H, et al., 2007).

Neste estudo a aplicação do "spray" baseou-se na vantagem econômica, uma vez que desta forma utilizase um menor volume de substância desinfetante. Além disso, o "spray" poder ser usado para qualquer material de moldagem, utilizando da mesma técnica preconizada por Linhares SMS, (2013), diferentemente da técnica de imersão dos moldes (QUEIROZ GL, et al., 2019).

Alguns estudos observaram o efeito do hipoclorito de sódio a $1 \%$, da clorexidina a $2 \%$, do hipoclorito $0,1 \%$ e do ácido peracético 0,2\% como desinfetante (QUEIROZ GL, et al., 2019; VASCONCELOS FC, et al., 2012), já o presente estudo optou por empregar além do ácido peracético $0,2 \%$ e clorexidina $2 \%$, hipoclorito de sódio 2,5\% e glutaraldeído $2 \%$, por serem substâncias largamente empregadas na Odontologia para desinfecção.

Apesar de todas as substâncias avaliadas não interferirem na reprodução de detalhes dos materiais elastoméricos testados, cabe ressaltar que além dessa característica, a substância para ser eleita como um ótimo desinfetante para materiais de moldagem, deve, entre outros fatores: possuir amplo espectro de ação, ser altamente eficaz, ser solúvel em água, poder ser usado como desinfetante e também esterilizante, não ser inativado por fluido ou matéria orgânica, ser atóxico, ser de fácil manipulação, ter boa durabilidade e não agredir o meio ambiente.

Dentre as substâncias analisadas, a única que reúne todas essas características, com ênfase na não toxicidade e por ser ecologicamente correta é o ácido peracético (RUTALA WA, et al., 2007). Essas características têm feito do ácido peracético uma substância bastante estudada atualmente, tanto na Odontologia (MOURA CDVSD, et al., 2016; NASCIMENTO ACD, et al., 2015) quanto em outras áreas (BARBOSA LS e SARTORI MRK, 2017; GILDO MGP, et al., 2018). Outra propriedade extremamente relevante de ser estudada, é a compatibilidade dos materiais de moldagem com o gesso. Vários outros autores estudaram a influência da desinfecção sobre modelo de gesso, porém a maioria deles avaliou as alterações dimensionais ocorridas em tais modelos (PAVARINA AC, et al., 1999; ZANET CG, et al., 2003). Maltez MM, et al, (2007), não observaram alterações dimensionais de modelos de gesso obtidos a partir de moldes de Zetaplus/Oranwash imersos em glutaraldeído e hipoclorito de sódio por 15 minutos. Neste experimento, em $100 \%$ dos modelos de gesso foi possível a visualização da linha central, fato este que denota a compatibilidade do gesso com o material de moldagem.

Um estudo avaliou influência do tempo de armazenamento na rugosidade, tração diametral e compressão de gessos odontológicos concluindo que quando da utilização dos gessos odontológicos na obtenção de modelos de trabalho, devemos manusear os mesmos pelo menos 24 horas após sua espatulação, minimizando os riscos de fraturas, trincas ou desgastes, devido ao aumento dos valores de compressão e tração diametral (CESERO L, et al., 2014). Para a rugosidade superficial dos gessos testados, os resultados mostram que não há diferença relevante clinicamente nos tempos estudados.

Por fim, os moldes que foram submetidos ao protocolo de desinfecção, independente da substância utilizada, bem como os moldes não contaminados com S. aureus, não apresentaram turvação dos respectivos meios de cultura nos quais foram incubados. O que significa dizer que o protocolo de desinfecção preconizado, teve ação antimicrobiana sobre as siliconas de moldagem estudadas.

Osório AF, et al., (1998), avaliaram a atividade antimicrobiana do hipoclorito de sódio e glutaraldeído, porém em moldes de alginato, concluindo que tais substâncias tiveram atividade antimicrobiana. Fato este, também observado por outros pesquisadores que avaliaram a efetividade do hipoclorito de sódio $1 \%$ e 
glutaraldeído $2 \%$ sobre os materiais contaminados com Staphylococcus aureus e concluíram que os protocolos de desinfecção foram eficazes na eliminação do microganismo. Já Silva FC, et al., (2008), avaliaram a aderência em aço inoxidável de Staphylococcus aureus antes e após ciclagem com glutaraldeído $2 \%$, vinagre $100 \%$ e ácido peracético $0,2 \%$ e concluíram que o ácido peracético foi a substância que demonstrou menor aderência do microrganismo (TAYLOR RL, et al., 2002).

Enquanto, Chassot ALC, et al. (2006), estudaram a ação antimicrobiana da imersão em ácido peracético de resinas acrílicas e observaram que tal substância foi eficaz na desinfecção. Mediante as diferentes pesquisas quanto à efetividade antimicrobiana parece que é unânime a eficácia antimicrobiana do ácido peracético, fato este também verificado neste estudo, onde foi formado um grupo controle positivo, que corresponde àqueles moldes contaminados que não foram submetidos à aplicação de nenhuma substância desinfetante, ocorrendo nesses grupos a turvação do meio de cultura, nos quais foram incubados. Este fato demonstra a necessidade de desinfecção dos moldes, opinião compartilhada pela maioria dos autores, porém não defendida por Sofou A, et al. (2002) que consideram os protocolos de desinfecção desnecessários, preconizando apenas procedimento de higiene, como a lavagem das mãos, para eliminar o risco de infecção cruzada para os profissionais de Odontologia.

Os resultados estão restritos ao microrganismo utilizado nesse estudo ( $S$. aureus), fato este que denota a necessidade de novos estudos para saber a ação antimicrobiana das substâncias desinfetantes sobre outros microrganismos presentes na cavidade bucal e possíveis responsáveis pelas infecções cruzadas no ambiente Odontológico. Assim como a metodologia pode ser utilizada para avaliar outros materiais de moldagem e outras substâncias desinfetantes.

\section{CONCLUSÃO}

Baseado nos resultados obtidos nesse estudo, é licito concluir que: 1). As substâncias; hipoclorito de sódio $2,5 \%$, glutaraldeído $2 \%$, clorexidina $2 \%$ e ácido peracético $0,2 \%$ possuem ação antimicrobiana sobre as siliconas testadas contaminadas com Staphylococcus aureus e 2). Tais desinfetantes não alteraram a reprodução de detalhes das mesmas, nem tampouco a sua compatibilidade com o gesso avaliado. Dessa forma, comprova-se a eficiência dos protocolos de desinfecção estudados, sendo estes indicados para a prática clínica/laboratorial por garantirem a desinfecção desses trabalhos, impedindo a infecção cruzada; sem alterar a reprodução de detalhes dos moldes de silicona nem dos modelos de gesso obtidos a partir destes.

\section{AGRADECIMENTOS E FINANCIAMENTO}

Agradecemos à Universidade Potiguar, local de realização do estudo.

\section{REFERÊNCIAS}

1. ABINAYA K, et al. Evaluation of surface quality of silicone impression materials after disinfection with ozone water: An In vitro Study. Contemporary clinical dentistry, 2018; 9(1): 60.

2. AMERICAN DENTAL ASSOCIATION. Infection control recomendationes for the dental office and the dental laboratory. Journal of the American Dental Association,1996; 127: 672-80.

3. BARBOSA LS, SARTORI MRK. Métodos de esterilização de artigos hospitalares efetivos conta micobactérias não tuberculosas de crescimento rápido. Cadernos da Escola de Saúde, 2017; 1(5): 136-153.

4. CHASSOT ALC, et al. In vivo and in vitro evaluation of the efficacy of a paracetic acid-based disinfectant for decontamination of acrylic resins. Braz. Dent J, 2006; 17(2): 117-121.

5. DE CESERO L, et al. The influence of postpouring time on the roughness, compressive strength and diametric tensile strenght of dental stones. The Journal of Prosthetic Dentistry, 2014; 112: 1573—77.

6. DE QUEIROZ GL, et al. Efeito de diferentes agentes desinfetantes na estabilidade dimensional de materiais de moldagem. Revista Eletrônica Acervo Saúde, 2019; 27(1): e916-e916.

7. GILDO MGP, et al. Avaliação da eficácia antimicrobiana de desinfetantes utilizados na rotina de limpeza hospitalar. Revista Expressão Católica Saúde, 2018; 2(2): 34-39.

8. GUIRALDO RD, et al. Influence of the disinfection technique in detail reproduction and dimensional change of plaster casts obtained from different alginate impression material molds. Journal of Advances in Medicine and Medical Research, 2016; 17 (9): 1-8. 
9. GUIRALDO RD, et al. Surface detail reproduction and dimensional accuracy of molds: influence of disinfectant solutions and elastomeric impression materials. Acta Odontológica Latinoamericana, 2017; 30 (1): 13-18.

10. GUPTA R, et al. Comparação de vários métodos de desinfecção de impressões hidrocolóides irreversíveis usando gluconato de clorexidina: Avaliação da eficácia antimicrobiana e alterações dimensionais. Jornal de Medicina Internacional e Odontologia, 2016; 3 (3): 151-160.

11. LINHARES SMS, et al. Desinfecção de moldagens na clínica integrada da Faculdade de Odontologia de Campos. International Journal of Science Dentistry, 2013; 2 (34): 36-42.

12. MALTEZ MM, et al. Avaliação dimensional de materiais de moldagem submetidos à desinfecção. Rev. fac. Odontol. Lins, 2007; 19 (1): 27-37.

13. MOURA CDVSD, et al. Analysis of the antimicrobial effectiveness of peracetic acid for the disinfection of irreversible hydrocolloid impressions. Revista de Odontologia da UNESP, 2016; 45 (6): 309-315.

14. NASCIMENTO ACD, et al. Estabilidade do ácido peracético no processo de desinfecção prévia à lavagem. Revista da Associacao Paulista de Cirurgioes Dentistas, 2015; 69 (4): 367-382.

15. NASSAR U, CHOW AK. Surface detail reproduction and effect of disinfectant and long-term storage on the dimensional stability of a novel vinyl polyether silicone impression material. J Prosthodont, 2015; 24: 494-8.

16. OSÓRIO AF, et al. Avaliação da eficácia de agentes químicos na desinfecção de moldes de alginato. Rev Fac Odontol Porto Alegre, 1998; 39 (1):17-19.

17. PAVARINA AC, et al. Infecção cruzada entre o consultório odontológico e o laboratório via próteses contaminadas. Rev Prot Clin Lab, 1999; 1 (1):74-78.

18. POULIS N, et al. Preliminary SEM observations on the surface of elastomeric impression materials after immersion or ozone disinfection. Journal of clinical and diagnostic research: JCDR, 2016; 10 (12): 1-5.

19. RUTALA WA, WEBER DJ. Disinfection of endoscopes: review of new chemical sterilants used for high-level disinfection. Infect. Control Hosp Epidemiol, 2007; 20: 69-76.

20. SAVABI O, et al. Prevention of cross-contamination risk by disinfection of irreversible hydrocolloid impression materials with ozonated water. International journal of preventive medicine, 2018; 9 (1): 37.

21. SILVA FC, et al. Influência de agentes desinfetantes sobre a aderência de Staphylococcus aureus em aço inoxidável. Cienc Odontol Bras. São José dos Campos, 2008; 11 (3): 60-65.

22. SILVA SMLM, SALVADOR MCG. Effect of the disinfection technique on the linear dimensional stability of dental impression materials. J Appl Oral Sci, 2004; 12 (3): 244-249.

23. SILVA TSDO, et al. Conducts of disinfection, pouring and storage of irreversible hydrocolloid impressions by undergraduate students. Revista de Odontologia da UNESP, 2016; 45 (1): 1-6.

24. SOFOU A, et al. In vitro study of bactéria from contaminated metal models to Stone models via impressions. Clin Oral Investig, 2002; 6 (1): 161-70.

25. TAYLOR RL, et al. Desinfection procedures: their effect on the dimensional accuracy and surface quality of irreversible hydrocolloid impression materials and gypsum casts. Dent Mater, 2002; 18: 103-110.

26. TSUZUKI FM, et al. Profile of victims of accidents with biological material in a course of Dentistry. RGO-Revista Gaúcha de Odontologia, 2019; 67.

27. VASCONCELLOS FC, et al. Estabilidade dimensional de modelos obtidos com poliéter e silicone de adição após desinfecção comácido peracético e hipoclorito de sódio. Revista Brasileira de Odontologia, 2012; 69 (1): 55-60.

28. YADAV BK, et al. Assessment of infection control practice in private dental hospital. International Journal of Research in Medical Sciences, 2017; 5 (11): 4737-4742.

29. YILMAZ H, et al. Effect of disinfection on the dimensional stability of polyether impression materials. Journal of Prosthodontics, 2007; 16 (6): 473-479.

30. ZANET CG, et al. Efeitos dos desinfetantes sobre hidrocolóide irreversível. Rev Paul Odont, 2003; 25 (3):14-17. 